\title{
LA INTRODUCCIÓN DEL ARTE FLAMÍGERO EN CASTILLA: PEDRO JALOPA, MAESTRO DE LOS LUNA
}

\author{
POR
}

\author{
AMALIA MARÍA YUSTE GALÁN
}

\begin{abstract}
Don Álvaro de Luna, en la cima de su poder, decide erigir una capilla funeraria en la catedral de Toledo. Relacionado con esta construcción aparece Pedro Jalopa, posiblemente, el mismo maestro que, unos años antes, había dirigido las obras de la catedral de Huesca bajo el mecenazgo del Papa Benedicto XIII, tío abuelo de Don Álvaro. Después de su intervención en Toledo, Jalopa fue contratado como maestro mayor de la catedral de Palencia. La poderosa familia de los Luna y las estrechas relaciones entre los obispados, pudieron influir en el itinerario artístico de Pedro Jalopa a lo largo de la primera mitad del siglo xv, época de la introducción de las formas flamígeras en Castilla.

Palabras clave: Arquitectura gótica; Catedral de Toledo; Capilla de Santiago; Pedro Jalopa.

Don Álvaro de Luna, at the height of his power, decided to build a funerary chapel in Toledo Cathedral. In relation to this project Pedro Jalopa appears, possibly the same master who some years earlier had directed the construction of Huesca Cathedral under the patronage of Pope Benedict XIII, great-uncle of Don Álvaro. After his work in Toledo, Jalopa was contracted as master builder at Palencia Cathedral. The powerful Luna family and the close relationship between bishoprics may well have influenced the artistic itinerary of Pedro Jalopa during the first half of the $15^{\text {th }}$ century, the period when flamboyant forms were introduced in Castille.

Key words: Gothic architecture; Toledo Cathedral; Chapel of Santiago; Pedro Jalopa.
\end{abstract}

\section{Primeras obras flamígeras en Castilla}

La llegada, durante el primer tercio del siglo xv, de artistas procedentes, principalmente, de los Países Bajos y Francia y, en menor medida, de Alemania, supuso la introducción de las formas flamígeras en Castilla. La buena situación económica, debida en gran parte al floreciente comercio de lanas, favoreció la construcción de numerosos monumentos: palacios, iglesias, capillas funerarias; obras encargadas por los reyes, los nobles, y el alto clero, que utilizaron estas nuevas formas artísticas como expresión del poder alcanzado.

Muchos pedreros llegaron a Castilla atraídos por las abundantes ofertas de trabajo, y quizás por la mayor libertad que podían tener en estas tierras donde los gremios todavía no eran tan rígidos o incluso, en algunas profesiones, no estaban constituidos ${ }^{1}$.

\footnotetext{
${ }^{1}$ En cuanto a las razones de la llegada de artistas extranjeros ver Yarza Luaces, J., «El arte de los Países Bajos en la España de los Reyes Católicos», en Reyes y Mecenas, Toledo, 1992, pp. 133-150; y del mismo autor, Los Reyes Católicos. Paisaje Artístico de una Monarquía, Madrid, 1993, p. 374.
} 
En arquitectura se mantuvieron las estructuras anteriores, a las que se añadió la rica decoración que caracterizaba la complicación ornamental de estos edificios, cuyos maestros manifestaron un sentido más escultórico que arquitectónico en sus obras.

Uno de los primeros ejemplos de la utilización de formas flamígeras en la arquitectura castellana se encuentra en la capilla funeraria que mandó construir el Contador Fernán López de Saldaña en la iglesia del convento de Santa Clara, en Tordesillas. Comenzada a construir en 1430, fue su aparejador Guillén de Rohan, según una inscripción hoy desaparecida ${ }^{2}$. López de Saldaña era criado y amigo de don Álvaro de Luna, y estos lazos que unían al Contador con don Álvaro ${ }^{3}$ hicieron posible que, junto a la familia de don Fernán López de Saldaña, se diera sepultura a la primera esposa del Condestable, doña Elvira de Portocarrero ${ }^{4}$. Una vez enterrada su primera mujer como correspondía a su linaje, podía don Álvaro erigir un panteón para su familia y su segunda esposa, doña Juana de Pimentel. Para ello don Álvaro de Luna, la figura de mayor relevancia en la corte de Juan II, solicitó un lugar en la catedral de Toledo. A pesar de tan osada petición, el cabildo, con su arzobispo a la cabeza, concedió a don Álvaro un emplazamiento privilegiado para su fundación en la cabecera del templo, junto a la capilla de San Ildefonso, comenzando en estos mismos años la construcción de la que será la capilla de Santiago para enterramiento suyo y de sus familiares.

La nueva capilla ocupó el lugar de tres pequeñas: la de San Eugenio, la de Santo Tomás de Canterbury y la de Santiago, que pertenecían a la primitiva girola, además del corral que llamaban de la Higuera hasta el taller de la calle de Azacanes, y del taller donde se labraban los moldes, que fue el lugar elegido para la sacristía ${ }^{5}$. La toma de posesión de dichos espacios tuvo lugar el 18 de abril de 1430, y durante la solemne ceremonia se señaló sobre el terreno, con un azadón, el perímetro que iba a ocupar la capilla. Entre otros, fueron testigos el alguacil mayor de la ciudad, don Pedro Carrillo de Toledo, Alvar Martínez, maestro mayor de la catedral, y los pedreros Diego Martínez, Alfonso Rodríguez, Alfonso Gómez, y Cristóbal Rodríguez.

Es, por lo tanto, Alvar Martínez en esos años el responsable de la dirección de las obras de la catedral. Su trabajo como pedrero ha sido documentado por Sánchez Palencia ${ }^{6}$, y como maestro mayor de la catedral fue analizado por el profesor Azcárate ${ }^{7}$. A su biografía podemos añadir el dato, hasta ahora inédito, de que era hijo de Alvar González, con quien se formó, y junto con quien trabajó en los talleres de la catedral desde finales del siglo $\mathrm{XIV}^{8}$.

\footnotetext{
${ }^{2}$ Merino Rubio, W., Arquitectura hispano-flamenca en León, León, 1995², pp. 30-31.

${ }^{3}$ Amistad que acabaría en odio. En el exterior de la capilla Saldaña, entre los escudos que aparecen está el del propio don Álvaro de Luna, explicado por la presencia del sepulcro de su primera mujer (véase nota 4), o bien por las consecuencias del posterior enfrentamiento con el Condestable, que supondrán además de la expulsión del contador de Castilla, el confiscamiento de todos sus bienes. Don Álvaro recibirá de Juan II todos los heredamientos y tierras confiscadas al Contador. Calderón Ortega, J. M., «Las rentas de las posesiones toledanas de Álvaro de Luna Condestable de Castilla y Maestre de Santiago», en I Congreso de Historia de Castilla la Mancha, Campesinos y señores en los siglos XIV y XV, Castilla la Mancha y América, Toledo, 1988, pp. 81-85.

${ }^{4}$ González Hernández identificó uno de los bultos de la capilla con el de doña Elvira de Portocarrero. González Hernández, A., «Un enterramiento en la capilla de Saldaña, en el monasterio de Santa Clara de Tordesillas (Valladolid)», en $B$. $S$ E. A. A., T. LVIII, 1992, pp. 301-312.

${ }^{5}$ El documento perteneciente al Archivo de los Duques del Infantado fue publicado por Barrera en 1882, y posteriormente, de forma completa, por González Palencia. Barrera, P. Ma., Sepulcro de Don Álvaro de Luna en la Capilla de Santiago, Madrid, 1882. González Palencia, C., «La Capilla de Don Álvaro de Luna en la Catedral de Toledo», en A. E. A. A., 1929, pp. 109-122.

${ }^{6}$ Los datos que se conocen de la participación de Alvar Martínez, como pedrero, en las obras de la capilla de San Blas fueron publicados por Sánchez-Palencia. Sánchez-Palencia Mancebo, A., «La Capilla del Arzobispo Tenorio», en A.E.A., T. XLVIII, $\mathrm{n}^{\circ} .189,1975$, pp. 27-42.

${ }^{7}$ Azcárate, además, aclara que Alvar González, con quien otros estudiosos habían confundido al maestro de la catedral, era el aparejador de la cantera de Olihuela. Azcárate y Ristori, J. Ma. de, «Alvar Martínez, Maestro de la Catedral de Toledo», en A. E. A., vol. XXIII, 1950, pp. 1-12.

${ }^{8}$ A.C.T., Sig. E. 9. A. 1. 19. Ver Apéndice, doc. $\mathrm{n}^{\circ} 1$.
}

$A E A$, LXXVII, 2004, 307, pp. 291 a 300 
La formación castellana del maestro Alvar Martínez supuso la continuidad de la tradición arquitectónica local hasta la aparición de las nuevas corrientes. A pesar de ello no se puede descartar que don Álvaro encargase al propio Alvar Martínez las trazas para su capilla funeraria, e incluso que dirigiese su construcción, junto con la de la catedral, hasta su muerte, ocurrida posiblemente a finales de $1437^{9}$, lo que explicaría que un año después se cite a otro maestro como responsable de la obra de dicha capilla.

Tampoco es extraño que un maestro diferente al que dirigía la fábrica catedralicia se encargase de una obra tan notable.

Construir una capilla en la propia cabecera de la Catedral Primada suponía un gran reto técnico y simbólico. El Condestable respondió a tan privilegiado emplazamiento con una magnífica construcción, utilizando para ello las suntuosas formas flamígeras que respondían a sus deseos de innovación como manifestación de su poder.

La necesidad de maestros para materializar este nuevo estilo, plantea una hipótesis distinta en cuanto a la historia de la construcción de la capilla de Santiago y la participación que en ella hubiera podido tener un maestro diferente a Alvar Martínez.

Una escueta nota sacada de una escritura de arrendamiento, fechada en mayo de 1438, da a conocer el nombre de Pedro Jalopa, al que denominan maestro de la capilla del condestable, fue publicada en 1919 por don Vicente Lampérez con ocasión del informe que presentó para la ampliación de la cripta de la capilla de Santiago ${ }^{10}$. La información se la facilitó el deán de la catedral don Narciso de Esténaga ${ }^{11}$.

A pesar de la responsabilidad que claramente se atribuye a Pedro Jalopa en este documento, la intervención de dicho maestro en la catedral toledana no ha sido tenida en cuenta, haciendo responsables de la obra de la capilla de Santiago a Alvar Martínez y al taller de Hanequín de Bruselas, maestro que dirigirá posteriormente las obras de la catedral.

Si bien es cierto que cuando se encarga la obra de la capilla el maestro mayor era Alvar Martínez, y que en 1437 todavía sigue siéndolo ${ }^{12}$, se puede pensar que el Condestable don Álvaro buscó para su capilla un modelo diferente al estilo tradicional representado por Alvar

\footnotetext{
${ }^{9}$ En el documento de agosto de 1437, Alvar Martínez además de ceder unas casas suyas y de su mujer, instituye una capellanía en la iglesia de San Justo, seguramente preocupado ya por su muerte. Desde este momento no volvemos a tener noticias del maestro, quien probablemente morirá a finales de ese año o principios del siguiente. A. C. T., Sig. E. 1. A. 3. 24. Ver Apéndice, doc. $\mathrm{n}^{\circ} 2$.

${ }^{10}$ Zabala, M. «Instancia del Sr. Duque del Infantado solicitando autorización para realizar obras en la capilla de Santiago de la ciudad de Toledo», Boletín de la Real Academia de Bellas Artes de San Fernando, 3. a época, año XIII, n. 49 , marzo 1919, pp. 4-6. La noticia que se publicó sólo menciona la fecha y que se tomó de una escritura de arrendamiento, pero no la serie documental a la que pertenece. Gilman Proske cita a Jalopa como pedrero mayor de la capilla del Condestable, haciendo referencia a la información publicada en el Boletín de la Real Academia de Bellas Artes. Gilman Proske, B., Castilian Sculpture. Gothic to Renaissance, New York, 1951, nota 98, p. 478. A. C. T., Protocolos, O. F., 1086, fol. XCIIIr. y XCIIIIr. Ver Apéndice, doc. nº 4.

${ }^{11}$ Don Narciso de Esténaga, siendo deán de Toledo, comenzó a elaborar una historia sobre la catedral. En 1922 fue nombrado obispo de Ciudad Real, donde continuará sus investigaciones. Desaparecido en la Guerra Civil, los manuscritos de su monumental obra fueron devueltos a Toledo, donde se mantuvieron durante años bajo llave. La consulta de sus cuadernos obliga a reconocer la inmensa labor de este historiador, a pesar de la dificultad que supone la pérdida de sus ficheros referenciales, por lo que su obra ha permanecido inédita hasta hoy. Gonzálvez Ruiz, R., «Observaciones sobre el libro del Dr. Rivera», en Toletum, n. ${ }^{\circ} 34,1996$, pp. 163-176.

${ }^{12}$ La serie de los Libros de Obra y Fábrica de la catedral, donde se anotaban los gastos de materiales y de mano de obra, no se ha conservado completa. Entre otros, faltan los libros correspondientes a los años de 1432 hasta 1448 . No podemos asegurar las obras que se llevan a cabo durante ese tiempo; en cuanto a la dirección, en 1432 todavía era maestro mayor Alvar Martínez, y en 1448 lo será Hanequín de Bruselas. Pero estudiando en las series de Protocolos los documentos de arrendamiento de las casas donde moraban, se pueden establecer unos límites más concretos para sus maestrazgos, la relación entre algunos de ellos y su vínculo con la ciudad. En muchas ocasiones el cabildo arrendaba casas de su propiedad a los maestros que trabajaban para la catedral, por lo que estos protocolos se conservan en el fondo catedralicio. Esta documentación nos ha permitido retrasar la presencia del maestro Alvar Martínez hasta 1437 y dar a conocer nuevos datos sobre el maestro Pedro Jalopa.
} 
Martínez; como así lo hizo, también, su criado y amigo, el no menos importante don Fernán López de Saldaña, en su capilla del convento de Santa Clara en Tordesillas ${ }^{13}$.

Don Álvaro era sobrino nieto de don Pedro Martínez de Luna, que desde 1394 estaba a la cabeza del pontificado de Avignon, con el nombre de Benedicto XIII. Al morir Juan Martínez de Luna, Benedicto XIII, su hermano, acogió bajo su protección a sus sobrinos Pedro, Álvaro y Rodrigo, que llegarían a desempeñar importantes cargos en la corte. Pedro de Luna, con el apoyo de su tío, fue promovido al arzobispado de Toledo (1403-1414) ${ }^{14}$; Álvaro ostentó el título de copero mayor del rey Enrique III y fue el padre del Condestable de Castilla, don Álvaro de Luna; y Rodrigo dirigió las tropas pontificias ${ }^{15}$.

Don Álvaro de Luna, que también quedó huérfano siendo niño, fue recogido por su tío el arzobispo don Pedro de Luna, que se encargó de su educación, y lo presentó en la corte en 1408; dos años después ya era paje del rey Juan II. Esta temprana relación se convirtió pronto en dependencia del joven rey hacia don Álvaro, al que otorgará los más altos honores del reino.

Pero ¿a quién encargaría el gran valido de Juan II, la misión de traducir en piedra su gran poder político? Si fue a Pedro Jalopa, ¿quién era este maestro? ¿De dónde venía? ¿Qué obras avalaban su traslado a Toledo para hacerse cargo de una construcción tan emblemática en la época como la capilla del Condestable de Castilla en la cabecera de la catedral?

En este trabajo se plantea la posibilidad de que fuera el mismo maestro que había dirigido la fábrica de otra gran catedral: la de Huesca, y que, posteriormente a su trabajo en Toledo, fuese llamado a Palencia, donde se documenta a Jalopa como maestro mayor de las obras de la catedral.

\section{Pedro Jalopa en Huesca}

El Papa Luna, gran humanista y mecenas, fue un destacado promotor de empresas artísticas, como las obras en la cabecera y el cimborrio de la catedral de Zaragoza y diferentes intervenciones en Calatayud, Daroca, Tarazona, y en la catedral de Huesca, a cuyo cabildo perteneció ${ }^{16}$.

Durante el primer tercio del siglo xv, gracias al apoyo y financiación de Benedicto XIII, las obras de la Catedral de Huesca recibieron un gran impulso: se tiran los restos que quedaban de la mezquita, se construye una crujía en el claustro, donde se conservan las claves con el escudo papal, se inicia la cubrición de la nave mayor y el remate de la torre, en el que está documentada la intervención del maestro Pedro Jalopa ${ }^{17}$.

En el archivo capitular de la catedral de Huesca sólo se conservan, de esta época, los libros referentes a los años 1422 y 1423. El último estudio sistemático de los documentos de

\footnotetext{
${ }^{13}$ Además de la coincidencia de fechas en la elevación de ambas capillas, se han apuntado posibles relaciones estilísticas. Azcárate y Ristori, J. Ma. de, Arte Gótico en España, Madrid, 1990, p. 241.

${ }^{14}$ Tras la muerte del arzobispo don Pedro Tenorio, la sede toledana permaneció varios años vacante. El cisma continuaba, y Enrique III había vuelto a la obediencia de Benedicto XIII, solemnemente anunciada en las cortes de Valladolid que se celebraron en 1403. Ese mismo año el Papa Luna, nombra como arzobispo de Toledo a su sobrino don Pedro de Luna. Nombramiento que no aprueban ni el rey, ni el cabildo, que había elegido al arcediano de Guadalajara don Gutierre Álvarez de Toledo. Rivera Recio, J. F., Los arzobispos de Toledo en la Baja Edad Media (s. XII-XV), Toledo, 1969, p. 99.

${ }^{15}$ Suárez Fernández, L., Benedicto XIII, Madrid, 2002, p. 21.

${ }^{16}$ El Papa y sus protegidos están relacionados con las primeras muestras del arte flamígero, esencialmente decorativas, en Aragón. En la Seo de Zaragoza, a principios del siglo xv, y costeado por Benedicto XIII se recrece el ábside con un cuerpo poligonal. En San Juan de la Peña entre 1426 y 1433 se levanta la capilla de San Victorián como lugar de enterramiento del abad Juan Marqués, nombrado en dicho cargo por el Papa Luna en 1412. Guitart Aparicio, C., Arquitectura Gótica en Aragón, Zaragoza, 1979, pp. 109-110.

${ }^{17}$ Lacarra Ducay, $\mathrm{M}^{\mathrm{a}}$. C., «Benedicto XIII y el Arte», en Muestra de Documentación Histórica Aragonesa en Conmemoración del Sexto Centenario de la Elección Papal de Don Pedro Martínez de Luna, Zaragoza, 1994, pp. 101-111.
}

$A E A$, LXXVII, 2004, 307, pp. 291 a 300 
dicho archivo fue realizado por el profesor Durán, que publicó la fecha en que se contrató a Jalopa. El 19 de enero de 1422, reunidos los canónigos rescindieron el contrato a Rodrigo Pérez, como maestro mayor de la obra de la Seu, y nombraron a maestre Pere Jalopa, con una retribución anual de tres cahíces de trigo, dos miestros de mosto y uno de vino malluelo, más 4 sueldos por jornal cada un día que en la dita obra obrara, con la obligación de fer continua habitación con su muller en Huesca ${ }^{18}$.

En 1422 trabajaban junto al maestro guiador de la obra, Pere Jalopa, a quien también se le denomina piquero, y que cobra 4 sueldos, sus mozos Arnaltón, con 2 sueldos y dos dineros, y Nicolau, que con los piqueros Pere Zacosta y Johan de Escalate ganaron 3 sueldos y 6 dineros. Además trabajaban quince manobreros temporales ${ }^{19}$.

En agosto de ese año Pedro Jalopa ajusta con el cabildo la obra de la torreta sobre el campanario de la Seo. El maestro firma un contrato en el que se detallan las condiciones siguiendo la muestra en papel que había presentado; el cabildo se compromete, por su parte, a facilitarle todos lo materiales a pie de obra y a reparar la grúa si esta se quebrase, como así ocurrió. Diego de Aynsa describe, tras su primera reforma, este último cuerpo pentagonal como un hermoso chapitel con sus torreoncillos, de unos doce metros de altura ${ }^{20}$.

En 1423 Pedro Jalopa, ayudado por un mozo, labró las pilas de agua bendita decoradas con esfullage, con un salario de 4 sueldos diarios. Durán también atribuye al maestro Jalopa la pila de bautizar ${ }^{21}$.

La desaparición del remate de la torre de la catedral, obra proyectada y ejecutada por Jalopa, impide conocer las características de este maestro. Sin el apoyo del análisis estilístico, sólo quedan las citas documentales para seguir su trayectoria.

Manteniendo la hipótesis de que el maestro que dirigió las obras de la catedral de Huesca ${ }^{22}$, llamado Pedro Jalopa, sea el mismo que se ha documentado en Toledo, se puede plantear el traslado del maestro de Huesca a Toledo por su relación con los Luna, uno de los linajes más influyentes desde finales del siglo xIV en los reinos de Aragón y Castilla.

\section{Pedro Jalopa en Toledo}

En Toledo, la primera noticia del maestro es de 1435, y aparece en un contrato de arrendamiento: el 20 de diciembre de ese año Jalopa y su mujer María Juana de Valladolid alquilan unas casas del cabildo en la Tripería Vieja, en la colación de San Justo. En este interesante documento se dice que Pedro Jalopa es vecino de la ciudad de Toledo, y actúa como su fiador el maestro de la obra Alvar Martínez ${ }^{23}$.

El establecimiento de Jalopa junto a su familia en Toledo, coincide con el aumento de trabajo que supuso el inicio de la gran capilla de Santiago en la cabecera del templo. Jalopa llegó

\footnotetext{
${ }^{18}$ Durán Gudiol, A., Historia de la Catedral de Huesca, Huesca, 1991, p. 106.

${ }^{19}$ Ibídem.

${ }^{20} \mathrm{La}$ única descripción que se conoce de la torre antes de sus repetidas transformaciones se debe a Diego de Aynsa, pero en esa época ya había sufrido una profunda reparación. Aynsa y Iriarte, D. Frc. de, Fundación, excelencias, grandezas y cosas memorables de la antiquisima ciudad de Huesca, ansi en lo temporal como en lo espiritual, Huesca, 1619, p. 515. Posteriormente fue reformada en los siglos XVI, XVII y XVIII; en el XIX, ante el peligro de desplome, se aprobó una nueva restauración, pero todo ello desaparecerá a consecuencia de una explosión durante la guerra civil. Durán Gudiol, op. cit., pp. 230-231.

${ }^{21}$ Ibídem, pp. 108-110.

${ }_{22}$ Del Arco, R., La catedral de Huesca, Huesca, 1924, p. 32. Torres Balbás, L.: «Arquitectura gótica» en Ars Hispaniae, T. VII, Madrid, 1952, p. 270. Martínez, R., La Arquitectura Gótica en la ciudad de Palencia (1165-1516), Palencia, 1989, p. 167.

${ }^{23}$ A. C. T., Protocolos, O.F. 1085, fol. CCXXVIIr y v, y CCXXVIIIv. Ver Apéndice, doc. nº 3.
} 
a Toledo para trabajar en su construcción, a la vez que se continuaban las obras de la catedral bajo la dirección de Alvar Martínez, con quien aparece estrechamente vinculado.

La siguiente noticia, siempre en relación con las casas en la colación de San Justo, es la que le documenta, en 1438, como maestro de la capilla del Condestable ${ }^{24}$. En 1442 sigue viviendo en las mismas casas, en esos momentos citadas en la calle de los Estantales ${ }^{25}$, las que abandonó antes de 1450. Pero todavía en ese año se mencionan en un documento recordando que en ellas había vivido el maestro Jalopa ${ }^{26}$.

En Toledo la desaparición de los Libros de Obra y Fábrica de estos años impide documentarlo como maestro mayor ${ }^{27}$, responsabilidad que no sabemos si llegó a desempeñar en esta catedral, ya que tras la muerte de Alvar Martínez pudo haberse incorporado al taller de Hanequín de Bruselas ${ }^{28}$. A este taller se han atribuido, tradicionalmente, las obras de la Capilla del Condestable, considerándolas, además, una de las razones de la llegada de estos maestros foráneos a Castilla.

Se ha podido documentar, sin embargo, que Hanequín era maestro mayor en $1442^{29}$, lo que adelanta en unos años su presencia en Toledo. Desde la desaparición de Alvar Martínez, ocurrida probablemente en 1437, hasta la llegada de Hanequín, en torno a 1442, hay un lapso de tiempo en el que Jalopa pudo haberse ocupado de la dirección de las obras.

En la capilla de Santiago se introducen las formas flamígeras, que se hacen patentes en los abundantes elementos decorativos de perfiles sinuosos adosados a los muros. Es un arte refinado y cortesano que se superpone a las estructuras góticas tradicionales, y que fue utilizado para poner de manifiesto el poder de una de las figuras más destacadas del momento.

\section{Pedro Jalopa en Palencia}

La estrecha relación de la catedral de Palencia con la de Toledo, convirtió la sede palentina en un paso importante en la carrera eclesiástica, que culminaría con el ascenso a la Primada ${ }^{30}$. Importantes obispos lo fueron primero de Palencia para después ser de Toledo ${ }^{31}$. Uno de ellos, con gran trascendencia en las obras de ambas catedrales, fue don Sancho de Rojas, obispo de Palencia entre 1403 y $1415^{32}$ y, posteriormente, nombrado también por Benedicto XIII, de Toledo de 1415 a 1422 .

\footnotetext{
${ }^{24}$ Véase nota 10

${ }^{25}$ Las casas en las que vivió el maestro Pedro Jalopa, identificadas por Jean Passini, están situadas en la esquina de la calle de la Tripería Vieja con los Estantales, por lo que según el documento aparecen citadas en una u otra calle. Passini, J., Casas y Casas Principales Urbanas. El Espacio Doméstico de Toledo a fines de la Edad Media, Toledo, 2004, pp. 301-310.

${ }^{26}$ A. C. T., Protocolos, O.F. 1088, fol. 40r y 42v. Ver Apéndice, doc. ${ }^{\circ}$ 5; y A. C. T., Protocolos, O.F. 1091, fol. 19v y 21r. Ver Apéndice, doc. 6.

${ }^{27}$ Véase nota 12.

${ }^{28}$ Quizás Jalopa tampoco fuera capaz de satisfacer las necesidades de innovación de don Álvaro, y sólo resolviera, junto a Alvar Martínez, los problemas técnicos, ya que suponían también un gran reto, al ocupar la nueva capilla un espacio con un desnivel de hasta siete metros. Esto explicaría la llegada a Toledo del taller de Hanequín.

${ }^{29}$ A. C. T., Registro de Escrituras, O. F. 1274 , fol. $39 \mathrm{v}, 51 \mathrm{v}$ y $72 \mathrm{v}$. Ver Apéndice, doc. n. ${ }^{\circ} 7$.

${ }^{30}$ Más tarde y como ejemplo de esta estrecha relación entre las dos diócesis, será obispo de Palencia Diego Hurtado de Mendoza (1471-1485), sobrino de don Pedro González de Mendoza, el gran cardenal. Ara Gil, C. J., «La actividad artística en la catedral de Palencia durante los obispados de Diego Hurtado de Mendoza y fray Alonso de Burgos (1471-1499)», en Jornadas sobre la Catedral de Palencia, Valladolid, 1989, pp. 68-69.

${ }^{31}$ Don Gutierre Álvarez de Toledo es obispo de Palencia de 1426 a 1439, año en que es promovido, con la ayuda de don Álvaro de Luna, al arzobispado de Sevilla, donde permanecerá hasta que sea nombrado arzobispo de Toledo en 1442 . VV. AA., Los Primados de Toledo, Toledo, 1993, p. 92.

${ }^{32}$ Don Sancho de Rojas impulsó los trabajos en la catedral palentina, llevando acabo destacadas obras. Desde Toledo seguirá las obras de su antigua sede. Martínez, R., «La Catedral y los obispos de la Baja Edad Media (1247-1469)», en Jornadas sobre la Catedral de Palencia, Valladolid, 1989, p. 49.
}

$A E A$, LXXVII, 2004, 307, pp. 291 a 300 
El vínculo entre las diócesis, y el interés que los obispos mostraban en seguir el avance de las obras de sus catedrales, permitió el conocimiento de los maestros que en ellas participaban; cuando en la catedral de Palencia se realizó un cambio en la dirección de sus obras, el cabildo necesitaría buscar a un maestro de reconocido prestigio y pudo haberlo hecho en Toledo donde, en esos años, Jalopa estaba trabajando ${ }^{33}$.

Rafael Martínez publicó el documento por el que se contrata, en septiembre de 1443, a Pedro Jalopa como maestro de la catedral de Palencia junto a Gómez Díaz, hasta esos momentos único responsable de la dirección de la obra, pagándoles a ambos el mismo salario ${ }^{34}$. Se ha querido buscar una justificación para esta doble contratación en un aumento de la actividad en las obras del templo, o por la necesidad de una maestro de sólida formación que pudiera orientar el cambio en las trazas de la iglesia que se llevará a cabo en estos años ${ }^{35}$. Si bien pueden ser ciertas ambas razones, lo sorprendente es que dos meses más tarde, el único maestro que consta es Gómez Díaz. Las explicaciones dadas para tan corta relación han sido una posible falta de entendimiento entre los dos maestros, o, tal vez, la imposición de Jalopa por el obispo de Palencia, a la sazón, don Pedro de Castilla Eril ${ }^{36}$. Pero si es cierto que se trata del mismo maestro que desde Huesca se trasladó a Toledo y de allí a Palencia, la razón más fácil para explicar su desaparición en Palencia es, posiblemente, su muerte ${ }^{37}$.

La situación que pudo provocar el traslado de Jalopa de Toledo a Palencia fue similar a la que se produjo en los años treinta en Toledo. El considerable aumento de trabajo que supuso la construcción de una gran capilla en la catedral Primada, además del reto técnico y simbólico al que se enfrentaban, obligaba a buscar a un maestro diferente al formado en los talleres toledanos. En Palencia, la decisión de cambiar el proyecto primitivo, con las dificultades que esto suponía para adaptarlo a lo ya ejecutado, y el incremento del trabajo, planteó, también, la necesidad de un nuevo maestro que colaborase con el que ya trabajaba dirigiendo las obras. Jalopa bien pudo aceptar la oferta de Palencia, donde posiblemente fuese requerido para contribuir a la solución del problema técnico, como ya lo hiciera antes en Huesca y en Toledo.

\section{Conclusión}

Pedro Jalopa aparece documentado como maestro mayor de la catedral de Huesca en 1422, período durante el cual, y bajo la protección del Papa Luna, se tira lo que quedaba de la antigua mezquita para construir una crujía del claustro, se remata la torre y se inicia la cubrición de la nave mayor. Posteriormente se cita a un maestro, también llamado Pedro Jalopa, que en

\footnotetext{
${ }^{33}$ Hanequín de Bruselas fue maestro mayor de la catedral de Toledo a partir de 1442 por lo que Jalopa, si alguna vez dirigió las obras, quedaría relegado ante la llegada del nuevo taller, y pudo aceptar la oferta de un cargo de mayor responsabilidad en Palencia.

${ }^{34}$ Martínez, R., «Gómez Díaz de Burgos (1430-1466), Maestro Mayor de la obra de la Catedral de Palencia», en P. I. T. T. M., no 58,1988 , pp. $417-426$.

${ }^{35}$ Conocemos otros casos en que maestros de gran prestigio son llamados por las obras de diferentes catedrales para resolver problemas técnicos. Es el caso del maestre Isambret o Isambart, que aparece citado en 1434 en la catedral de Sevilla. Pudiera tratarse del mismo maestro que trabajando en Daroca, es llamado por el Cabildo de la Seo de Zaragoza, en 1417, para consultar los problemas que presentaba el Cimborrio, y en 1424 era maestro mayor de la Catedral de Palencia. Falcón Márquez, T., «El edificio Gótico», en La Catedral de Sevilla, Sevilla, 1991, pp. 142.

${ }^{36}$ Martínez, R., art. cit., p. 419. Todos los investigadores coinciden en que el comienzo de una nueva etapa en las obras de la catedral de Palencia se da durante el episcopado de los obispos don Gutierre Álvarez de Toledo (1423-1439) y don Pedro de Castilla Eril (1440-1461).

${ }^{37}$ En Huesca era maestro mayor de las obras en 1422, cargo que difícilmente desempeñaría antes de los treinta años, si no era mayor. A partir de 1443 no volverá a aparecer citado en la documentación palentina; y en Toledo, aparece su nombre en un contrato de arrendamiento de 1450 para decir que las casas en las que antes vivía maestre Jalopa pertenecen a otras personas. Véase nota 26.
}

AEA, LXXVII, 2004, 307, pp. 291 a 300 
1435 aparece asentado en la ciudad de Toledo, donde alquila unas casas en la Tripería Vieja, contrato en el que es avalado por el propio maestro de la catedral Alvar Martínez. Tres años más tarde, y muerto ya Alvar Martínez, Jalopa aparece como responsable de la capilla de don Álvaro de Luna. En 1442 las casas de Toledo, siguen perteneciendo al maestre Jalopa que, seguramente, y si se trata del mismo maestro, no las abandone a pesar de ser llamado a Palencia, donde se le cita en 1443 como maestro mayor de la catedral junto a Gómez Díaz, año en el que, probablemente, murió, por lo que no se vuelven a tener noticias suyas.

Si todos los documentos se refieren a la misma persona, podemos considerar a Pedro Jalopa un destacado maestro de este período, cuyo itinerario artístico estuvo marcado por la familia de los Luna: el Papa Benedicto XIII tío abuelo del Condestable de Castilla y los obispos por él nombrados, el arzobispo de Toledo don Pedro de Luna, y el propio don Álvaro. Bajo la influencia de este poderoso linaje, y gracias a la estrecha relación entre los obispados, el mismo maestro pudo haber sido requerido en las obras de las catedrales de Huesca, Toledo y $\mathrm{Pa}-$ lencia en la primera mitad del siglo xv.

\section{APÉNDICE DOCUMENTAL}

\section{ALVAR MARTÍNEZ}

Doc. 1

1409, Junio, 4. Toledo.

Carta de Venta de unas casas a Alvar Martínez pedrero, en la colación de San Lorenzo, por precio de seis mil maravedís. Pasó ante Diego Alfonso escribano.

«Sepan quantos esta carta vieren como yo pero gonçales fijo de miguel ferrandes de la rred veçino morador en el arraval de toledo por mi e en nonbre de Johan gonçales my hermano fijo del dicho miguel ferrandes mi padre e por poder que del he para vender la su meytad de unas casas que el e yo avemos aqui en Toledo en la collaçion de la eglesia de sant lorenço las quales dichas casas se tienen con casas bodega de doña Juana de covisa e con casas de rrodrigo alfonso fijo de rrodrigo Alfonso e con la calle [del Rey] Et con la otra meytad de las dichas casas que son de mi el dicho pero gonçales Et por el presçio e preçios que yo pudiere a quien quisiere e por bien toviere por ende yo el dicho pero gonçales por mi e en nonbre del dicho Juan gonçales mi hermano e por el dicho poder que de el he segund que en esta carta se contiene otorgo e conosco que vendo a vos Alvar martines pedrero fijo de Alvar gonçales vesino morador en toledo unas casas que yo e el dicho mi hermano Avemos aqui en toledo en la collaçion de la eglesia de sant lorenço... por presçio çierto e sabido e contado seys mill maravedis de esta moneda usual que fasen dos blancas un maravedi los quales seys mill maravedis dichos rresçeby yo pero gonçales el dicho vendedor de vos alvar martines pedrero el dicho conprador por mi en nonbre del dicho Juan gonçales mi hermano e pasaron a $\mathrm{mi}$ poder... fecha e otorgada en toledo quatro dias de Junio del Año del Nasçimiento de Nuestro Salvador Ihesu Christo de mill e quatroçientos Et Nueve Años...».

En las espaldas: «San lorenzo $\mathrm{n}^{\circ} 33 »$. «Carta de alvar martines pedrero de las casas de su morada». En otra letra: «De las casas del maestro de la obra...».

A. C. T., Sig. E. 9. A. 1.19

Doc. 2

1437, Agosto, 21. Toledo.

Carta de donación por la que Alvar Martínez, jurado y maestro de la obra de Santa María de Toledo, y su mujer donan unas casas que tienen en la colación de San Lorenzo a los capellanes de la catedral, con obligación de celebrar unos aniversarios a su muerte en la iglesia de San Justo. Pasó ante Joan González de Espinosa, escribano público.

«... Por ende sepan quantos esta carta de donaçion vieren como yo alvar martines Jurado de la eglesia de sant yuste desta muy noble çibdat de toledo e maestro de la obra de señora santa maria de la dicha cibdat e yo mari gutierres su muger del dicho alvar martines mi marido... otorgamos e conosçemos que fazemos graçia e çesion e donaçion pura e perfecta e libremente... a vos los Capellanes de la hermandat del choro de señora santa maria la mayor de la dicha çibdat de toledo con que yo el dicho alvar martines Jurado e maestro tenga

$A E A$, LXXVII, 2004, 307, pp. 291 a 300 
hemandat de unas Casas que nos los dichos alvar martines Jurado e maestro e mari gutierres su muger avemos e tenemos en esta dicha çibdat de toledo en la collaçion de la eglesia de señor sant lorenço de esta dicha çibdat que han por linderos de la una parte Casas que fueron de pero manrrique e de la otra parte casas del honrrado e discreto varon don pero alfonso de valladolid abad de san viçente de la sierra Canonigo en la dicha eglesia de toledo E la calle publica Real las quales dichas casas que suso dichas e deslindadas son que vos asy damos e donamos son con tal postura e condiçion que sy yo el dicho alvar martines maestro fallesçiere antes que la dicha mi muger que la dicha mi muger biva e este e se aproveche en todos los dias de su vida de las dichas casas e frutos e Rentas de ellas tanto que las non pueda vender nin dar nin donar... vosotros los sobre dichos hermanos de la dicha hermandat que seades tenudos de dezir e cantar en cada un año dos aniversarios en la eglesia de señor sant yuste de esta dicha cibdat de toledo por las animas de mi el dicho alvar martines maestro e de mis defuntos e que despues de los dias de la dicha mari gutierres mi muger que seades tenudos de dezir e cantar en cada un año quatro aniversarios por las animas de nos los dichos alvar martines e mari gutierres e de nuestros defuntos... alvar martines maestro e mari gutierres su muger otorgamos esta carta de donaçion en la manera que dicha es ante el escrivano e notario publico e ante los testigos de yuso escriptos... fue fecha e otorgada en la muy noble cibdad de toledo a veynte e un dias del mes de agosto del año del nasçimiento del nuestro salvador Ihesu Christo de mill e quatroçientos e treynta e syete años...»

En las espaldas: «San lorenzo $n^{\circ}$ 63. Donaçion del maestro de la obra e de su muger de unas casas en la colaçion de sant lorenzo». Encima, en otra letra: «alvar martines Jurado».

A. C. T., Sig. E. 1. A. 3. 24.

\section{PEDRO JALOPA EN TOLEDO}

Doc. 3

1435, Diciembre, 21. Toledo.

Carta de arrendamiento de Pedro Jalopa y su mujer de unas casas del cabildo en la Tripería Vieja, en la colación de San Justo.

Fol. CCXXVIIr: «perpetuo de las casas que tomo Jalopa pedrero e maria Juana de valladolid su muger veçinos de Toledo».

«Sepan quantos este publico instrumento de perpetuo vieren commo nos çebrian sanches lugarteniente del dean e Juan lopes de burgos mayordomo e Canonigos de la yglesia de Toledo en nombre de los señores Cabildo de la dicha yglesia otorgamos e conosçemos que arrendamos a vos pedro Jalopa maestro de pedreria veçino de Toledo e a vos maria Juana su muger que estades presentes unas casas que los dichos señores cabildo han tienen e poseen en esta dicha çibdad a la triperia vieja que son a la collaçion de sant yuste que han por linderos de la una parte casas de la dicha yglesia que tiene en Renta gonçalo garçia carpintero e marina rrodrigues su muger E de la otra parte ...... [está en blanco] E la calle publica Real las quales dichas casas antes de la dicha yglesia tenian en Renta por su vida pascual garçia barvero e marina garçia su muger... e fixieron dexamiento de las dichas casas en favor de vos los dicho pedro Jalopa e maria Juana su muger... fol. CCXXVIIv: ... E yo el dicho pedro Jalopa asy conosco que le di e do la dicha liçençia a la dicha maria Juana mi muger E yo la dicha maria Juana asy conosco que Reçeby e Recibo del dicho mi marido amos a doss commo prinçipales debdores e alvar martines maestro de la obra de la dicha yglesia commo su fiador todos tress de mancomun... fol. CCXXVIIIv: ... fechas e otorgadas en la muy noble çibdad de Toledo a veynte de dizienbre año del nasçimiento de nuestro salvador Ihesu Christo de mill e quatroçientos e treynta e çinco años».

A. C. T., Protocolos, O. F. 1085.

Doc. 4

1438, Mayo, 5. Toledo.

Carta de arrendamiento de unas casas bodega a Lope Rodríguez en la Tripería Vieja, las cuales lindan con las casas que tiene arrendadas el maestre Pedro Jalopa, maestro de la capilla del Condestable.

Fol. XCIIIr: «... Arrendamos a vos lope Rodrigues carpintero e leonor gomes su muger que presentes estades unas Casas bodega que los dichos señores cabildo han E tienen E poseen en esta dicha çibdad a la collaçion de santo yuste a la triperia vieja que dizen la bodega de los estantales que han por linderos de la una parte Casas que de la dicha yglesia tyene maestre pedro de Jalopa pedrero maestro de la capilla del condestable E de la otra parte de Arriba bodega de los frayles de la sysla ... fol. XCIIIIr: ... fechas e otorgadas en la muy noble çibdad de Toledo A çinco dias del mes de mayo año del nasçimiento de nuestro salvador Ihesu Christo de mill e quatroçientos e treynta e ocho Años...».

A. C. T., Protocolos, O. F. 1086. 
Doc. 5

1442, Abril, 18. Toledo.

Casas del tesorero don Alonso Martínez en los Estantales que lindan con las casas en las que mora el maestre Pedro Jalopa.

Fol. 40r: «Sepan quantos este publico Instrumento vieren como dentro en el cabildo de la eglesia cathedral de la muy noble çibdad de toledo dies e ocho dias del mes de abril Año del Nasçimiento del nuestro Salvador Ihesu Christo de mill e quatroçientos e quarenta e dos años... el dicho cabildo tiene unas casas en esta dicha çibdad a la collaçion de sant yuste a los estantales que han por linderos de la una parte casas del dicho cabildo en que mora maestre pedro Jalopa pedrero e de la otra parte casas de fernand Ruys çerero que son tributarias a la dicha eglesia e la calle del Rey las quales dichas casas suso deslindadas son de poca Renta e Inutiles a la dicha eglesia e cabildo e non Rinden cosa alguna por estar derrocadas en el suelo e porque costarian mucho faser de Nuevo e rendirian poco Por ende pidieron Al dicho señor dean provisor e vicario general suso dicho que les diesen liçençia para las poder dar in infiteosin Al honrrado don alfonso martines thesorero e canonigo de la dicha eglesia que presente estava con cargo e tributo que de e pague en cada un año al dicho cabildo sesenta maravedis de moneda vieja o al doblo de la moneda que corriere e se usare al tiempo... fol. 42v: ... fueron fechas e otorgadas en la muy noble çibdad de Toledo A dies e ocho dias del mes de abril Año del Nasçimiento del nuestro Salvador Ihesu Christo de mill e quatroçientos e quarenta e dos años...».

A. C. T., Protocolos, O. F. 1088.

Doc. 6

1450, Agosto, 8. Toledo.

Carta de arrendamiento a Pedro de Palencia, sombrerero, y a su mujer de unas casas en los Estantales, en la que se cita como lindero las casas en las que antes solía morar el maestre Pedro Jalopa.

Fol. 19v: «Pedro de Palençia».

«Sepan quantos esta carta de arrendamiento perpetuo vieren como Nos el dean e cabildo de la santa eglesia de Toledo estando ayuntados Capitularmente dentro en nuestro cabildo segund que lo avemos de uso e costunbre otorgamos e conosçemos que arrendamos a vos pedro de palençia sonbrerero veçino de toledo que estades presente $\mathrm{E}$ a cathalina Rodrigues vuestra muger que esta ausente unas casas que son en esta dicha çibdad A los estantales en la Collaçion de sant yuste que han por lynderos de la una parte casas que tyene maestre lope Carpintero E de la otra parte casas que tyene pero garçia Recuero las quales dichas casas antes solia tener maestre pedro Jalopa $\mathrm{E}$ ansy vos las Arrendamos... fol. $21 \mathrm{r}$ : ... en la muy noble çibdad de toledo en el dicho cabildo a ocho dias del mes de agosto año del Nasçimiento del nuestro salvador ihesu Christo de mill e quatroçientos e çinquenta años...».

A. C. T., Protocolos, O. F. 1091.

\section{HANEQUÍN DE BRUSELAS}

Doc. 7

1442, Febrero, 13. Toledo.

Hanequín de Bruselas, maestro de las obras de la iglesia, aparece como testigo en el libro de Registro de Escrituras de 1442, en los meses de febrero, marzo y junio.

Fol. 39v: «En XIII de febrero de XLII».

«... En la capilla de San Ildefonso los señores dean e cabildo... los dichos señores dieron su bastante poder... e a los honrrados Alonso garçia bachiller e pero gonçales de ocaña canonigo e In solidum para faser las Rentas de los sus vestuarios e es en el partido de alcala de los años de XXXIX, XL, e XLI pasados e les arrendar e faser... Fueron testigos ferrand clerigo de cibdat Real diego Alonso pertiguero e hanequin maestro de la obra de la dicha eglesia».

Fol. 51v: «XIIII de março».

«...e hanequin maestro de la obra de la dicha eglesia».

Fol. 72v: «En primero de Junio de XLII».

«... arrendaron las casas que solia tener Alonso de villa Real notario a la collaçion de sant yuste a Juan ferrandes pedrero veçino de Toledo presente por su vida perpetuamente... dio por su fiador a maestre hanequin maestro de la obra de la dicha eglesia obligaronse de mancomun...».

A. C. T., Registro de Escrituras, O.F., 1274.

AEA, LXXVII, 2004, 307, pp. 291 a 300 